\title{
Comment on Trivalent Europium Lifetimes in the Presence of Intramolecular Energy Transfer Processes
}

\author{
L. D. Carlos, ${ }^{*, a}$ W. M. Faustino ${ }^{b}$ and O. L. Malta ${ }^{*, b}$ \\ ${ }^{a}$ Departamento de Física and CICECO, Universidade de Aveiro, Aveiro, 3810-193 Portugal \\ ${ }^{b}$ Departamento de Química Fundamental-CCEN, Unversidade Federal de Pernanbuco, \\ Cidade Universitária, 50670-901 Recife-PE, Brazil
}

\begin{abstract}
Este trabalho enfatiza a importância de se distinguir conceitualmente tempos-de-vida na ausência (tempos-de-vida naturais) e na presença de processos de transferência de energia intramolecular em compostos de coordenação com lantanídeos. O foco do artigo trata de compostos de európio trivalente com ligantes mistos, e uma análise de caso é feita sobre resultados apresentados recentemente na literature.
\end{abstract}

This work emphasizes the importance of conceptually distinguishing between lifetimes in the absence (natural lifetimes) and in the presence of intramolecular energy transfer processes in lanthanide coordination compounds. It is focused on trivalent europium compounds with mixed ligands, and a case study is made on results recently reported in the literature.

Keywords: intramolecular energy transfer, lanthanides, coordination compounds, luminescence

\section{Introduction}

Intramolecular energy transfer is a key step for the high luminescence quantum yields observed in certain lanthanide compounds with organic ligands. Since the first demonstration in 1942 by Weissman ${ }^{1}$ that a major part of the energy strongly absorbed by the ligands in the UV is efficiently transferred to the central lanthanide ion, a number of works has appeared in the literature dedicated to the elucidation of the mechanisms governing the energy transfer processes and to the search for schemes in which these compounds could be modelled for applications in photonic devices. ${ }^{2-5}$

It is generally agreed that the luminescence quantum yield, usually defined as the ratio between the number of photons emitted by the lanthanide ion and the number of photons absorbed by the ligands, is the result of a balance between absorption, decay (radiative and non-radiative) and transfer rates in the compound, and can be described by an appropriate system of rate equations in the steady state regime. ${ }^{5}$ Nevertheless, a deeper investigation in

\footnotetext{
*e-mail: 1carlos@ua.pt; oscar@renami.com.br
}

the literature reveals that in these descriptions there is often a misunderstanding on the concept of excited state lifetime as measured in the laboratory from decay curves. This fact is of paramount importance, once it might lead to serious erroneous conclusions concerning the energy transfer processes. The aim of the present study is to call attention to this very fact and to throw some light on the treatment of the problem. As a case study, an alternative interpretation is provided to the results reported by Young et al. ${ }^{6}$

\section{Theoretical Discussion}

Prior to a more detailed discussion, it is worthy to recall the general fact in which in a kinetic process; like in chemical reactions and in the interaction of radiation with matter; the slower step determines the overall velocity of the process. For our purposes, we consider the four level systems shown in Figure 1, where we assume that at the instant $\mathrm{t}=0$ only state $|2\rangle$ is populated, with an initial population $\mathrm{N}_{2}^{0}$. This scheme applies to trivalent europium coordination compounds with mixed ligands, as in the case reported by Young et al. ${ }^{6}$ The purpose is to analyze the temporal evolution of the system as a function of the rates Wij. 


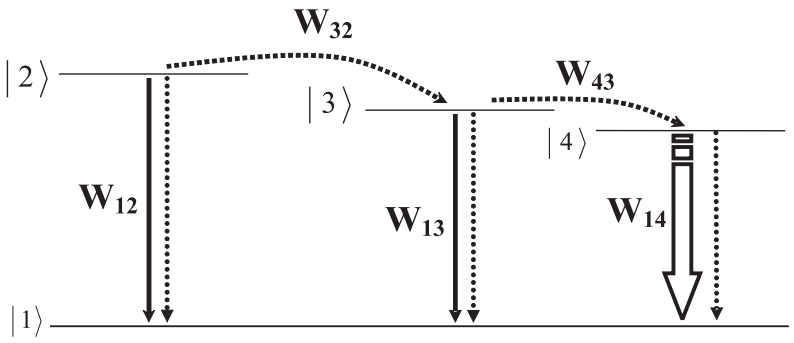

Figure 1. Schematic four energy level diagram involving intramolecular energy transfer channels.

For the sake of clarity a common ground state, $|1\rangle$ is assumed. The rates $\mathrm{W}_{12}, \mathrm{~W}_{13}$ and $\mathrm{W}_{14}$ include both radiative and non-radiative decays, while $\mathrm{W}_{32}$ and $\mathrm{W}_{43}$ correspond to intramolecular energy transfer rates. To keep as much as possible the generality of the analysis we will not specify the multiplicity of states $|2\rangle$ and $|3\rangle$, except when required by the discussion, and it is conceivable that they may be located at different parts in the coordination sphere of the compound. State $|4\rangle$ corresponds to the emitting level of the lanthanide ion.

The appropriate system of rate equations is

$$
\begin{aligned}
& \frac{\mathrm{dN}_{1}}{\mathrm{dt}}=\mathrm{W}_{12} \mathrm{~N}_{2}+\mathrm{W}_{13} \mathrm{~N}_{3}+\mathrm{W}_{14} \mathrm{~N}_{4} \\
& \frac{\mathrm{dN}_{2}}{\mathrm{dt}}=-\left(\mathrm{W}_{12}+\mathrm{W}_{32}\right) \mathrm{N}_{2} \\
& \frac{\mathrm{dN}_{3}}{\mathrm{dt}}=-\left(\mathrm{W}_{13}+\mathrm{W}_{43}\right) \mathrm{N}_{3}+\mathrm{W}_{32} \mathrm{~N}_{2} \\
& \frac{\mathrm{dN}}{\mathrm{dt}}=-\mathrm{W}_{14} \mathrm{~N}_{4}+\mathrm{W}_{43} \mathrm{~N}_{3}
\end{aligned}
$$

In setting up the above system of rate equations we have made two simplifying assumptions. The first one was the neglect of energy back-transfer rates and the second one was to consider that the ground state is little depleted, or that $\mathrm{N} 1 \cong \mathrm{N}$, where $\mathrm{N}=\sum_{\mathrm{k}=1}^{4} \mathrm{~N}_{\mathrm{k}}$. These assumptions are physically reliable and do not affect the conclusions of the present discussion as far as the level diagram in Figure 1 applies.

We wish firstly to focus on the temporal behaviour of level $|3\rangle$ that feeds the emitting level of the lanthanide ion. The analytical solution for the population $\mathrm{N}_{3}$ is

$$
\mathrm{N}_{3}(\mathrm{t})=\frac{\mathrm{W}_{32} \mathrm{~N}_{2}^{0}}{\left[\left(\mathrm{~W}_{13}+\mathrm{W}_{43}\right)-\left(\mathrm{W}_{12}+\mathrm{W}_{32}\right)\right]}\left[\mathrm{e}^{-\left(\mathrm{W}_{12}+\mathrm{W}_{32}\right) t}-\mathrm{e}^{-\left(\mathrm{W}_{13}+\mathrm{W}_{43}\right) \mathrm{t}}\right]
$$

with a maximum at

$$
\mathrm{t}_{\max }=\frac{\ln \left[\left(\mathrm{W}_{13}+\mathrm{W}_{43}\right) /\left(\mathrm{W}_{12}+\mathrm{W}_{32}\right)\right]}{\left[\left(\mathrm{W}_{13}+\mathrm{W}_{43}\right)-\left(\mathrm{W}_{12}+\mathrm{W}_{32}\right)\right]}
$$

corresponding to the rise time of level $|3\rangle$. At $t=t_{\max }$ the population of level $|3\rangle$ is, therefore,

$$
\begin{aligned}
\mathrm{N}_{3}^{\max }= & \frac{\mathrm{W}_{32} \mathrm{~N}_{2}^{0}}{\left[\left(\mathrm{~W}_{13}+\mathrm{W}_{43}\right)-\left(\mathrm{W}_{12}+\mathrm{W}_{32}\right)\right]}\left[\left(\frac{\mathrm{W}_{13}+\mathrm{W}_{43}}{\mathrm{~W}_{12}+\mathrm{W}_{32}}\right)^{-\frac{\mathrm{W}_{12}+\mathrm{W}_{32}}{\mathrm{~W}_{13}+\mathrm{W}_{43}}}-\right. \\
& \left.\left(\frac{\mathrm{W}_{13}+\mathrm{W}_{43}}{\mathrm{~W}_{12}+\mathrm{W}_{32}}\right)^{-\left[\frac{\mathrm{W}_{13}+\mathrm{W}_{43}}{\left(\mathrm{~W}_{13}+\mathrm{W}_{43}\right)-\left(\mathrm{W}_{12}+\mathrm{W}_{32}\right)}\right]}\right]
\end{aligned}
$$

The lifetime, $\tau_{3}$, of level $|3\rangle$, as measured from the decay curve of this level, is the time interval at which $\mathrm{N}_{3}=(1 / \mathrm{e}) \mathrm{N}_{3}^{\max }$. Thus, from equations (5) and (7) one gets

$$
\begin{gathered}
{\left[\mathrm{e}^{-\left(\mathrm{W}_{12}+\mathrm{W}_{32}\right) \tau_{3}}-\mathrm{e}^{-\left(\mathrm{W}_{13}+\mathrm{W}_{43}\right) \tau_{3}}\right]=\frac{1}{\mathrm{e}}\left[\left(\frac{\mathrm{W}_{13}+\mathrm{W}_{43}}{\mathrm{~W}_{12}+\mathrm{W}_{32}}\right)^{-\frac{\mathrm{W}_{12}+\mathrm{W}_{32}}{\mathrm{~W}_{13}+\mathrm{W}_{43}}}-\right.} \\
\left.\left(\frac{\mathrm{W}_{13}+\mathrm{W}_{43}}{\mathrm{~W}_{12}+\mathrm{W}_{32}}\right)^{-\left[\frac{\mathrm{W}_{13}+\mathrm{W}_{43}}{\left(\mathrm{~W}_{13}+\mathrm{W}_{43}\right)-\left(\mathrm{W}_{12}+\mathrm{W}_{32}\right)}\right]}\right]
\end{gathered}
$$

At this point it is worthy to distinguish between the natural lifetime (the lifetime of a molecular or atomic excited state in the absence of energy transfer processes) and the lifetime when intramolecular energy transfer is operative, simply referred to as excited state lifetime, which is the measured (observed) lifetime in the laboratory in the presence of energy transfer processes. In the case of level $|3\rangle$, the former is simply given by the inverse of the decay rate $\mathrm{W}_{13}$. However, the latter must be obtained from equation (8), and it should be noticed that it is not simply given by the inverse of $\left(\mathrm{W}_{13}+\mathrm{W}_{43}\right)$, as it is sometimes assumed. From the above equations it can be seen that $\tau_{3} \cong\left(\mathrm{W}_{13}+\mathrm{W}_{43}\right)^{-1}$ only when $\left.\left.\left(\mathrm{W}_{12}+\mathrm{W}_{32}\right)\right\rangle\right\rangle\left(\mathrm{W}_{13}+\mathrm{W}_{43}\right)$. On the other hand, for $\left(\mathrm{W}_{12}+\mathrm{W}_{32}\right)\left\langle\left\langle\left(\mathrm{W}_{13}+\mathrm{W}_{43}\right)\right.\right.$, $\tau_{3} \cong\left(\mathrm{W}_{12}+\mathrm{W}_{32}\right)^{-1}=\tau_{2}$. Thus, it is clearly seen that an observation of a long lifetime of level $|3\rangle$ does not imply that the energy transfer rate $\mathrm{W}_{43}$ cannot be high. In this case, the observed lifetime, $\tau_{3}$, would be completely dominated by the slower step $\left(\mathrm{W}_{12}+\mathrm{W}_{32}\right)$.

A similar analysis can be made for the temporal evolution of level $|4\rangle$. The population $\mathrm{N}_{4}(\mathrm{t})$ can be readily obtained from equations (4) and (5). In this case, one finds that for $\left.\left.\mathrm{W}_{13}+\mathrm{W}_{43}\right)\right\rangle\left(\mathrm{W}_{12}+\mathrm{W}_{32}\right)$ and $\mathrm{W}_{14}$, two situations may be raised. If $\left.\left.\mathrm{W}_{14}\right\rangle\right\rangle \mathrm{W}_{12}+\mathrm{W}_{32}$ then the lifetime of level 
|4) will also be dominated by the slower step $\left(\mathrm{W}_{12}+\mathrm{W}_{32}\right)$ and $\tau_{4} \cong \tau_{2}$. On the other hand, if $\mathrm{W}_{14}\left\langle\left\langle\mathrm{~W}_{12}+\mathrm{W}_{32}\right.\right.$ then $\tau_{4} \cong 1 / \mathrm{W}_{14}$, which is the natural lifetime of level $|4\rangle$.

The results reported by Yang et al. ${ }^{6}$ might be a typical case that deserves to be analyzed under the light of the above theoretical discussion. There, the authors claim that in their compound the ligand triplet level does not participate in the intramolecular energy transfer process. In their $\mathrm{Eu}(\mathrm{III})$ compound with one dipyrazolyltriazine derivative (L) and three thenoyltrifluoacetonate (TTA) ligands the triplet states of L and TTA lie very close in energy and are both in good resonance conditions with the ${ }^{5} \mathrm{D}_{1}$ and ${ }^{5} \mathrm{D}_{0}$ levels of the Eu(III) ion. It is well known that the TTA triplet state is a highly efficient donor to the ${ }^{5} \mathrm{D}_{1}$ and ${ }^{5} \mathrm{D}_{0}$ excited states of $\mathrm{Eu}(\mathrm{III})$, with theoretically estimated transfer rates of the order of $10^{8} \mathrm{~s}^{-1}$. $^{5}$

The data reported by Yang et al. ${ }^{6}$ in which the observed triplet state has a considerably long lifetime (3.9 s), may be alternatively interpreted as follows. The compound is excited at both the singlet state and the charge transfer state in the ligand L, which lie far below the singlet state of the TTA ligand, subsequently populating the triplet state of L. This triplet state then transfers energy to both the triplet state of TTA and to the Eu(III) ion with rather low rates due to the facts that it is located far apart and it has a small dipole strength, which is corroborated by its considerably long lifetime. Thus, in this scheme, even though the transfer rate from the TTA triplet state to the Eu(III) ion is considerably high $\left(10^{8} \mathrm{~s}^{-1}\right)$, its lifetime is governed by the lifetime of the triplet state of the ligand L.

A similar analysis applies to the case of the emitting ${ }^{5} \mathrm{D}_{0}$ level of the $\mathrm{Eu}(\mathrm{III})$ ion. In their compound, emission from this level is still observed after $1 \mathrm{~s}$. This is a clear indication that the ${ }^{5} \mathrm{D}_{0}$ is still being populated after $1 \mathrm{~s}$ from the excitation flash. Since $\mathrm{W}_{14} \approx 10^{3} \mathrm{~s}^{-1}$, and given that the observed triplet lifetime is $3.9 \mathrm{~s}$, the situation $\left.\left.\mathrm{W}_{14}\right\rangle\right\rangle \mathrm{W}_{12}+\mathrm{W}_{32}$ indicates that $\left(\mathrm{W}_{12}+\mathrm{W}_{32}\right) \approx 1-10 \mathrm{~s}^{-1}$. However, for the ${ }^{5} \mathrm{D}_{0}$ level the excitation is made at $417 \mathrm{~nm}$, which is close to the ${ }^{5} \mathrm{D}_{2}$ level, particularly it is in very good resonance with the energy difference between the ${ }^{5} \mathrm{D}_{3}$ and ${ }^{7} \mathrm{~F}_{1}$ levels, the latter having at $77 \mathrm{~K}$ a thermal population around $1 \%$. In this case the ${ }^{5} \mathrm{D}_{0}$ is being popu- lated by an extra channel. This explains the two decay curves observed for this level, one in the millisecond scale, via the ${ }^{5} \mathrm{D}_{2}$, and the other one in the time scale longer than $1 \mathrm{~s}$, via the triplet states.

\section{Conclusions}

It is important to notice that the above discussion does not exclude the participation of the singlet state of $\mathrm{L}$ in the process. Actually, the transfer rate from this singlet state to the $\mathrm{Eu}$ (III) ${ }^{5} \mathrm{D}_{1}$ manifold might be considerably high. However, it is our conclusion that in this compound the data does not imply in the exclusion of the triplet states, neither of the ligand L nor of the TTA.

\section{Acknowledgments}

The authors gratefully acknowledge the support from the CNPq (Brazilian Agency), RENAMI project (Brazilian Molecular and Interfaces Nanotechnology Network), FCT (Portuguese Agency) and FEDER .

\section{References}

1. Weissman, S. I.; J. Chem. Phys. 1942, 10, 214.

2. Buono-Core, G. F.; Li, H.; Marciniak, B.; Coord. Chem. Rev. 1990, 99, 55.

3. Crosby, G. A.; Alire, R. M.; Whan, R. E.; J. Chem. Phys. 1961, $34,743$.

4. Horrocks Jr., W. De W.; Albin, M.; In Progress in Inoganic Chemistry; Lippard, S. J., ed.; John Wiley \& Sons: New York, 1984.

5. De Sá, G. F.; Malta, O. L.; Mello Donegá, C.; Simas, A. M.; Longo, R. L.; Santa-Cruz, P. A.; Da Silva Jr., E. F.; Coord. Chem. Rev. 2000, 196, 165.

6. Yang, C.; Fu, L. -M.; Wang, Y.; Zhang, J. -P.; Wong, W. -T.; Ai, X. -C.; Qiao, Y. -F.; Zou, B. -S.; Gui, L. -L.; Angew. Chem. Int. Ed. 2004, 43, 5010.

Received: September 21, 2007

Published on the web: February 29, 2008 